\title{
Hidalgo en la historia
}

\author{
Discurso de ingreso pronunciado por el Sr. Dr. don Edmundo \\ O'Gorman*
}

Señor Director de la Academia, el señor Marqués de San Francisco,

Señores académicos,

Señoras y señores:

La ominosa situación del mundo en que hemos vivido me ha empujado insensiblemente a adoptar, con los años, la actitud del gato escaldado que aconsejaba el viejo Herodoto, medroso de toda novedad, no fuera a traer consigo la cólera de"las potencias invisibles. Así, siempre que recibo una carta, y no se diga un telegrama o una llamada de larga distancia, tiemblo ante la posible amenaza a mi sosiego tan a codazos conquistado. No para mi el "vive peligrosamente" del enajenado Federico Nietzsche. Doble, pues, mi contento cuando recibí la misiva de esta ilustre Academia anunciándome, no su decisión de poner en el Indice mis borrones y trabajos, sino la de premiar mis esfuerzos con el espaldarazo que he venido a recibir esta noche. Sean, entonces, de gratitud mis primeras palabras por el honor que me confieren, señores académicos, al recibirme entre ustedes como miembro numerario de su corporación.

Pero en esta Academia es de estatuto que el agrado del ingreso venga enlutado por la ausencia de quien ya no volverá jamás; en este caso, por la del señor académico Dr. D. Pablo Martínez del Río.

Nació este señor el día 10 de mayo del año en que celebraba el orbe el cuarto centenario del primer viaje a tierras que más tarde se concebirian como nuestra América, augurio, tal parece, de la futura dedicación de aquel niño a resolver el gran arcano de cómo y cuándo fueron pobladas. Después de cursar los estudios medios en el colegio jesuítico de Stonyhurst, subió, como se dice allá, a la Universidad de Oxford donde empezó a cultivar su vocación de antropólogo y de historiador del remoto pasado. Esto entre los años de 1910 y 1914 cuando en México ardía la tea revolucionaria que redujo a ceniza, entre tantas otras fortunas, la de su familia. Huérfano ya de padre, ingresó el joven oxoniano a enfrentarse a una dificil situación, para él particularmente adversa por la inevitable, pero no por eso menos injusta hostilidad que, como maldición bíblica, alcanzaba a los vástagos de las familias más estrechamente vinculadas al régimen porfirista. $Y$ hace falta decir esto, porque el valor y la dignidad que él y muchos como él mostraron en aquellos años no constituyen, ciertamente, el menor de los méritos. En un viaje a España en 1922 contrajo matrimonio con doña Maria Josefa Fernández de Henestroza y poco tiempo después,

* Tomado de Memorias de la Academia Mexicana de la Historia (correspondiente de la Real de. Madrid), t. XXIII, con permiso del autor y de Academia. 
instalado en México, inició su carrera en la docencia y en el cultivo de la historia.

Largo sería enumerar los puestos magisteriales y los empleos académico-administrativos aue sirvió durante su laboriosa vida. Baste recordar que fue director de la Escuela de Antropología e Historia, y en nuestra Universidad, de la de Verano, de la Facultad de Filosofía y Letras y del Instituto de Historia que fundó en 1945 con D. Rafael Garcia Granados. Como profesor se distinguió en el servicio de las cátedras de Historia Antigua, Medieval y de México, de Protohistoria y Prehistoria y de Arqueología clásica. A lo largo de su vida ingresó en numerosas sociedades científicas nacionales y extranjeras y fue honrado con dos doctorados honoris causa.

Su pluma se reveló fecunda, y tanto, que estaría fuera de todo propósito tratar de citar aquí los títulos de las notas, traducciones, artículos y libros menores que nos ha dejado. Conformémonos, entonces, con sólo mencionar su obra capital. Los origenes americanos, que apareció en 1936 y notablemente ampliada, en 1943 y 1952. Carezco de autoridad para emitir un juicio sobre ese libro, pero aunque la tuviera no haria falta, porque ya tenemos al respecto el formidable testimonio de su excelencia en el volumen de homenaje que le presentaron amigos, colegas y discípulos con motivo del vigésimo quinto aniversario de la primera edición de la obra.

Incompleta como por necesidad tiene que ser esta reseña; lo sería imperdonablemente si no recordáramos siquiera la feliz incursión que hizo el Dr. Martínez del Río en el campo de nuestra Arqueología. Aludo, claro está, a las exploraciones que inició y dirigió en el sitio del templo mayor de Tlatelolco, cuyas ruinas, según hoy se admiran, son por eso y en cierto modo un monumento a su memoria.

$Y$ si es verdad, como lo es, que la belleza alegra la vida y la hace más llevadera, a D. Pablo hemos de reconocerle, además, el mérito de haber contribuido a ello en grado de excelente perfección en las gentiles personas de sus hijas a quienes en testimonio de la amistad que su padre tuvo con el mío, dedico el siguiente discurso.

Fue tan violenta, tan devastadora la revolución acaudillada por Hidalgo que siempre nos embarga la sorpresa al recordar que sólo cuatro meses estuvo al mando efectivo de la hueste. En el increíblemente corto espacio de ciento veinte días, aquel teólogo criollo, cura de almas pueblerinas, galante, jugador y dado a músicas y bailes: gran aficionado a la lectura y amante de las faenas del campo y de la artesanía, dio al traste con un gobierno de tres siglos de arraigo, porque si la vida no le alcanzó para saberlo, no hay duda que fue él quien hirió de muerte al Virreinato. David y Goliat. solian decir sus panegiristas. ¿Cómo no asombrarnos, entonces. del traúma que le provocó a la sociedad de la época el cariz tempestuoso y tumultuario de aquella rebelión? Y sobre todo ¿cómo no comprender el pasmo entre quienes, amigos suyos, admiraban en él, disimulando flaquezas, la clara inteligencia y los 
sentimientos benévolos y progresistas? No muy distinto sería nuestro horror, si mañana desayunáramos con la nueva de que Justino Fernández habia asaltado en la madrugada el Palacio Nacional al frente de los barrenderos de la ciudad y de los detenidos en los separos de la Procuraduría.

Quienes pretenden -y son legión- hacernos creer en el alzamiento de Hidalgo como el episodio inicial de una lucha entre buenos y malos, harian bien en tener presente aquel desconcierto para enjuiciar con más tolerancia reacciones inmediatas como la tan censurada excomunión que fulminó Abad y Queipo y para comprender, además, la acrimonia que predominó durante la primera etapa de la insurgencia. Españoles y criollos, por igual, le acumularon al sacerdote rebelde la suma de epítetos que atesora nuestra lengua para el vilipendio. Pero a este respecto conviene distinguir entre cargos e insultos, aunque lo primero suele sonar a lo segundo. Asi, cuando el Fiscal del Santo Oficio dice del Cura que, entre otras cosas, era hereje, apóstata, deísta, materialista, libertino, sedicioso, lascivo, judaizante, traidor y secuaz de las sectas de Sergio, Berengario, Cerinto, Carpocrátes y de otras que desenterró para lucimiento de su erudición, no es que lo injurie, como tampoco el agente del Ministerio Público de nuestros días a quien indicia de la comisión de un delito. Pero descontado todo eso, todavía queda el imponente cúmulo de denuestos que le dedicaron a Hidalgo sus enemigos. Sin mencionar los que mejor están para callados, podemos entresacar lo siguiente a manera de ejemplo: soberbio endemoniado, oprobio de los siglos, Sardanápalo, sicofanta descarado, clérigo espadachín, capitán de bandoleros y asesinos, aborto del pueblo de Dolores, injerto de los animales más dañinos, y otras lindezas por el estilo.

Pero a esta imagen de execración se opone la que nos han conservado los documentos procedentes del campo contrario. Hidalgo, en efecto, no sólo conservó entre los suyos el renombre de sabiduria y de bondad que le conquistaron sus afanes académicos y los esfuerzos que desplegó por mejorar las condiciones de vida de sus feligreses, sino que, decorado con el tratamiento de Alteza Serenísima y exaltado al pedestal de héroe magnánimo e invicto, de defensor de la religión y del pueblo, acabó por emprender un vuelo trascendental: predilecto hijo de María en su advocación de Guadalupe, apareció esplendoroso en el cielo de Jalisco como el elegido de Dios, el mesías de la regeneración de la Nueva España, el hombre providencial, el primero de los muchos que, quizá más para mal que para bien, se ha dignado enviar entre nosotros la Majestad Divina.

Monstruo luciferino y ángel de salvación, he aquí la extraña' dualidad con que penetró Hidalgo en el reino del mito donde las balas ya no pudieron alcanzarlo. Así transfigurado descendió a la Tierra, y en torno a la pugna entre aquellos extremos irreductibles se fue convirtiendo en el genio tutelar de nuestra historia. En las páginas siguientes queremos rastrear las huellas que en esa peregrinación ha dejado tan ilustre sombra.

No lograda todavía la independencia ya hay, respecto a Hidalgo, 
un pro y un contra, aún entre quienes la desatan y luchan por ella. Rayón y Morelos ven en el pronunciamiento de Dolores el antecedente bélico de la rebelión que encabezan, pero, además, vinculan ideológicamente ambos acontecimientos al considerar a Hidalgo como el inspirador de los ideales democráticos y republicanos adoptados por ellos. Pese a lo discutible de semejante filiación, el hecho es de gran importancia, porque no sólo le comunicó unidad histórica a los once años de lucha, sino porque esa fue la base que halló la Reforma para convertir a Hidalgo en su bandera, la vía por la cual alcanzará su más alto honor como padre de la patria.

Pero aquella primera utilización de la figura de Hidalgo, nacida, me parece, de la necesidad de crear un centro de unión a la lucha armada, no encontró eco unánime. Un escritor tan insospechable en la simpatía por la causa de la independencia como es el Padre Mier, piensa, es cierto, que el grito de. Hidalgo se justifica como reacción frente al despotismo y a las condiciones vejatorias en que estaba la mayoría de los habitantes de la Nueva España. La sublevación de 1810 le parece, sin embargo, insensata y desastrosos sus efectos, como encabezada que fue, dice, por un hombre ilustrado y emprendedor, pero ayuno de ideas y de talento político, autor de excesos y crímenes, y sobre todo, por un hombre que en lugar de incurrir en el ridículo de otorgarse títulos y tratamientos pomposos, debió preocuparse por darle cohesión y semblanza de legalidad al movimiento que desencadenó. Hidalgo, concluye Mier, "no fue un santo, ni santa la obra que emprendió" y agrega, "jamás un abismo semejante de males y crímenes me arrancará demasiados panegíricos". Según esta opinión, el pronunciamiento de 1810 fue un episodio negativo, nada glorioso y desligado de la verdadera lucha por la independencia, de suerte que lejos de vincular a Hidalgo a los ideales republicanos, el P. Mier cree en. la sinceridad de la invocación por parte de aquél del nombre de Fernando VII, el tirano que él, el P. Mier, tanto detestaba.

\section{III}

Ahora entra en la escena el gran rival, el otro candidato a la paternidad de la independencia: D. Agustín de Iturbide. A éste, como a su antiguo jefe Calleja, los insurgentes siempre le parecieron una cuadrilla de ladrones y asesinos que sólo procuraron el provecho propio y el engrandecimiento personal. Repetidas veces afirmó que si el tiempo echara marcha atrás volvería a perseguirlos con las armas, y lo más que pudo concederles fue que el desastroso ejemplo que dieron sirvió para fijar la opinión pública en el sentido de que la guerra a los españoles residentes en el país era injusta e insensata y que la única base para cimentar la futura felicidad de la patria consistía en la unión de todos los habitantes, sin distinción de origen, ni de raza. Y puesto que ese fue el fundamento principal del Plan de Iguala, no es difícil comprender que Iturbide haya repudiado con vehemencia la noción, después tan general, de que no había hecho sino consumar la obra comenzada por Hidalgo. Para Iturbide, pues, las revoluciones de 1810 y 1821 eran acontecimientos enteramente desligados e incompatibles, y la obvia consecuencia resultaba ser que a él y solamente a él correspondía la gloria de haber independizado la Nueva España. 
Es innegable que Iturbide disfrutó de un inmenso prestigio a raiz de su triunfo; no tanto, sin embargo, como para que los antiguos insurgentes aceptaran de grado su tesis. Les parecía que sin un Hidalgo no habría un Iturbide y les repugnaba el monopolio de gloria que pretendía reclamar para sí el Generalísimo-Almirante. Así las cosas, Iturbide, que con toda evidencia no recordaba bien su Maquiavelo, cometió el error tácito de permitir la creación, frente a su poder casi omnímodo, de otro poder infusilable, es decir, colegiado, donde se atrincheraron sus enemigos y las tendencias republicanas. No tardó en estallar la sorda pugna que todos sabemos, y no fue el menor de sus síntomas el tenaz empeño de los miembros de la Soberana Junta Gubernativa y más tarde de los del Congreso para obtener el reconocimiento oficial del mérito de los servicios prestados por los insurgentes, y el de la obligación en que, según ellos, estaba la patria de conmemorar las hazañas de sus jefes y honrar las cenizas de los que habian sido sacrificados. Al desprevenido que lea las actas de los largos debates suscitados con esos motivos, podrá parecerle frívolo el gasto de tiempo en asunto a primera vista tan trivial y pensará que habría sido mejor empleado en ventilar la gran cuestión para la cual fue convocado el Congreso. Pero la verdad es que, bien visto, no otra cosa se discutía, porque un voto en favor de la memoria de Hidalgo había adquirido el sentido de un voto republicano.

Por lo tanto, la pretensión era sacar a la insurgencia del limbo histórico en que quiso hundirla Iturbide, sin ninguna idea de negarle a éste el mérito de sus servicios. Sólo se insistió, pues, en que se aceptara que la revolución de Hidalgo era el antecedente y la condición de posibilidad de la de Iguala. No otros, en efecto, fueron los sentimientos que expresó el regidor Sánchez de Tagle en presencia de Iturbide en la composición poética que leyó el día en que hizo su entrada el Ejército Trigarante a la ciudad de México. Pero más ilustrativo es el proyecto que tenía D. Carlos María de Bustamante para perpetuar la memoria de la independencia y de quienes él consideraba sus autores. Propuso que, depósitos de inmundicias, se arrasaran las cuatro fuentes de la Plaza de Armas para substituirlas por cuatro columnas consagradas a Hidalgo, Allende, Morelos y Mina. Serían, dice, truncadas en señal de que esos héroes comenzaron la obra de libertad sin concluirla. A Iturbide propone que se le dedique una inscripción en el pedestal de la columna a la independencia que debería levantarse en la Plaza de Santo Domingo, y sugiere como texto el siguiente: "Al ciudadano Agustín de Iturbide y Aramburu, porque en el espacio de siete meses concluyó con medidas prudentes más bien que con armas, la obra de la libertad e independencia mexicana, comenzada desgraciadamente once años antes". No hace falta mucha imaginación para adivinar lo que el tal proyecto le parecería a aquel ciudadano.

Es sensible carecer de tiempo para relatar el forcejeo entre el Congreso e Iturbide empeñado éste en torpedear toda decisión de aquél que fuera favorable a la memoria de los insurgentes. Al respecto lo más interesante son los dictámenes de las Comisiones de Premios y Eclesiástica, encargada la última, de proponer la res- 
puesta que debería darse a una consulta del impresor Zúñiga y Ontiveros que no sabia, el pobre, qué festividades nacionales deberían aparecer en la próxima edición de su Calendario, ni qué notas explicativas darles a las que se aceptaran como tales. Sin poder entrar en los sabrosos detalles, baste advertir que la importancia de esos documentos estriba en que en sus resoluciones alcanzó Hidalgo el primero de los triunfos póstumos. Veamos en seguida los términos de la victoria.

Mientras Iturbide tuvo poder lo más que logró el partido insurgente fue la inclusión del 16 de septiembre en dos decretos sobre fiestas nacionales. No era, en verdad, gran cosa. Pero una vez derrocado Iturbide, nulificada su coronación, declarado traidor vitando, decretada la insubsistencia del Plan de Iguala y de los Tratados de Córdoba, ahuyentada el águila imperial por el águila democrática y anticipado el voto en favor del sistema republicano federal, el Congreso dedicó sus últimos alientos a organizar la gran promoción histórica de la insurgencia, que no otra cosa significa su famosa ley del 19 de abril de 1823.

Tan proscritos andaban los insurgentes que por increíble que hoy parezca, el legislador estimó necesaria la declaración legal de ser "buenos y meritorios" los servicios que prestaron. Se ocupó en seguida de la manera de calificarlos y de premiarlos, y despachados asi los vivos volvió la mirada hacia los muertos. Se empezó por declarar beneméritos en grado heroico a Hidalgo y a otros jefes de la insurgencia, y a continuación se explicó que el honor de la patria reclamaba el desagravio de sus cenizas. A este efecto. se exhumarían los restos de aquellos héroes; se depositarian en una caja que se traería a la ciudad de México; se edificaría en Catedral un sepulcro con una leyenda alusiva; se inscribirian sus nombres en el salón de sesiones del Congreso, y finalmente, los lugares donde fueron sacrificados se "cerrarán, dice el texto de la ley, con verjas, se adornarán con árboles y en su centro se levantará una sencilla pirámide que recuerde a la posteridad el nombre de sus primeros libertadores". Parece que vemos una viñeta en una antología de versos románticos.

Llegado el 17 de septiembre, el día prefijado en la ley y que en lo sucesivo se consagró como aniversario de sufragio por las almas de los muertos en la causa de la patria, la ceremonia se desarrolló con la mayor solémnidad posible. La caja que contenia los restos fue llevada desde la garita de Peralvillo hasta la iglesia de Santo Domingo en una carroza tirada, dice la crónica, por "personas decentes". Al otro día se la trasladó en procesión y bajo palio a la Catedral. Allí el diputado Dr. Argandar predicó el incendiario sermón que provocó en la plebe el intento de profanar aquella noche el sepulcro de Hernán Cortés, y celebrados los oficios fúnebres, la caja fue depositada provisionalmente en la bóveda debajo del altar de Los Reyes en espera del grandioso monumento que iba a levantarse y del que, según D. Lucas Alamán, solamente se llegaron a hacer dos estatuas por Patiño.

Fue así como legalmente pasó Hidalgo de cabecilla de salteadores a iniciador de nuestra independencia. Aún le falta un largo y 
agitado recorrido para su promoción final a padre de la patria. Iturbide, en cambio, quedó degradado. Ciertamente se reconoce que continuó la obra iniciada en 1810 , pero no que la hubiere concluido, porque se piensa que bastardeó su programa y sus ideales y que, con la implantación del Imperio, hubo una regresión al estado de esclavitud colonial. Se admite, pues, que Iturbide consiguió la emancipación del dominio español, pero que la independencia que se creia haber conquistado fue enteramente ilusoria. Iturbide es ahora la víctima de una metamorfosis parecida a la que sufrió Hidalgo: al que fue el "sin par hombre de los siglos y enviado del cielo" se le descubre el torvo perfil del traidor, y como Hidalgo, también tendrá que morir en el patíbulo para que su sombra ronde las gradas del templo de Clio en busca de su pedazo de gloria.

Al instalarse el segundo Congreso Constituyente (después vendrán tantos que mejor será perder la cuenta) ya estaba decidida la adopción del régimen federal. Para los efectos de esta historia, el hecho significa el arraigo definitivo de la insurgencia como el antecedente del liberalismo mexicano. Nada de extraño, pues, que en el Manifiesto que se publicó al promulgarse la Constitución de 1824 encontremos articuladas en una interpretación oficial las ideas expuestas en el apartado anterior.

La guerra de independencia, se lee en aquel notable documento, tuvo, sin duda, su principio en la revolución de Hidalgo, pero ha sido un error considerar que terminó en 1821. Toda la época iturbidista pertenece todavia a la lucha. Esta sólo concluye ahora que se ha implantado la democracia. Resulta, entonces, que el verdadero sentido de los catorce años transcurridos entre 1810 y 1824 consisten en que se trata de un periodo de acumulación de la experiencia política e ideológica que requerían los mexicanos para convencerse del arcaismo del sistema monárquico y de su inadecuación a las circunstancias peculiares del Nuevo Mundo, pero sobre todo, para aceptar la verdad trascendental del credo democrático, el régimen que la Naturaleza ha querido para el hombre. Sólo ese tipo de organización social, continúa diciendo el documento, no traiciona la meta que se propuso Hidalgo, y por eso, del mismo modo que en su día, Iturbide no le concedió a la empresa insurgente más mérito que el de haber fijado la opinión püblica en favor de su Plan de Iguala, así, ahora, el Congreso no le concede a Iturbide otro servicio que el de haber constituido un centro de unidad para las provincias y con su trágica muerte, el de haberse convertido en perpetua admonición para todo aquél que en el futuro pretenda "gozar, dice el Manifiesto, de todas las ventajas reservadas al cuerpo entero de la sociedad". En un decreto posterior (27 de noviembre de 1824) el Congreso selló su interpretación al abolir todas las fiestas civiles del calendario iturbidista y ordenar que solamente se guardaran como tales el 16 de septiembre y el 4 de octubre, los aniversarios, según la nueva tesis, del principio y del fin de la guerra de independencia.

Seguramente se habrá advertido que el Congreso desenterró la vieja idea de vincular el pronunciamiento de Hidalgo con los idea- 
les republicanos. Pero la novedad es ahora, que no sólo se consigue concebir de ese modo la suma de sucesos transcurridos desde 1810 como un esfuerzo unitario, sino, más a fondo, como un proceso teleológico con meta en la implantación del fedēralismo. La independencia dejó, por lo tanto, de entenderse como mero rompimiento de los lazos de la dominación española y al llenarse de un contenido específico, se ecuaciona con el advenimiento de la república.

\section{VII}

No se requiere mucha perspicacia para advertir que si la lucha por la independencia se concibe como el proceso de realización en México de los ideales democráticos, será necesario explicar la empresa de Hidalgo de acuerdo con esa idea. La tesis del Congreso de 1824 se convirtió, pues, en el a priori de los futuros historiadores de filiación liberal para quienes el pronunciamiento de 1810 será, ciertamente una sublevación armada contra el poder español, pero necesaria y más entrañablemente una cruzada del evangelio democrático y de su verdadera iglesia, la república federal. Buen ejemplo, nos parece, de la primacía de las exigencias políticas en la elaboración de las verdades de la historia.

Pero, además, semejante condicionamiento obligará a destacar por encima de los otros caudillos, a la figura de Hidalgo, venerada hasta ese momento como benemérita y heroica, pero colectivamente con ellos. El motivo de la preferencia es obvio, porque, dada la personalidad y los antecedentes del Cura, la suprema responsabilidad ideológica del movimiento tenía que gravitar naturalmente sobre él y porque la vaguedad en las expresiones de su pensamiento se presta a toda clase de aventuras hermenéuticas. No por eso dejará Hidalgo de ser el intrépido campeón de la tea encendida y de la espada que indudablemente fue; pero empezará a ser, además, el iluminado profeta del republicanismo. Junto al generalísimo empieza a erguirse el legislador y el teórico revolucionario. $\mathrm{Y}$ de aquí procede que la historiografía posterior haya planteado como problemas centrales de la comprensión del movimiento de 1810 , primero, el de determinar quién fue su verdadero promotor, si Hidalgo o Allende, y segundo, si se procedió de acuerdo con un plan político premeditado y bien definido. En torno a estas cuestiones han soplado, con torrentes de tinta erudita, los vendavales de la apologia y de la deturpación; pero no puede ya sorprendernos que al triunfo del partido liberal haya sido a Hidalgo a quien se le concedió la primacía en la iniciación de la independencia, pese a los méritos de Allende como conspirador más activo y más antiguo y tampoco que se haya sostenido, contra abrumadoras instancias, que el Cura procedió no ya sólo de acuerdo con un plan más o menos indefinido, sino con todo un programa que, claro está, anticipaba con genial clarividencia al que habia salido triunfante bajo las banderas victoriosas de la República.

Eclipsado el sacerdote novo-hispano, aparece en trazos cada vez más firmes la imagen de un santo laico que parece escapado de alguna página de Bernardino de Saint-Pierre. Es el venerable filósofo virgiliano de corazón sensible que despreció los honores y 
placeres de la vida cortesana y que humilló su genio al establecer su morada entre los humildes. Vive en estrecha comunión con ellos; llora en silencio sus desdichas; comparte sus sanas alegrías; alivia sus miserias, y en las tardes luminosas los reúne al pie de una robusta encina para instruirlos en los derechos ciudadanos y redimirlos del abismo de ignorancia en que los tiene sepultados la más cruel e injusta de las tiranías. Pero llegado el día asignado por el Supremo Autor de la Naturaleza de quien es él el instrumento, su amor a la humanidad doliente lo transfigura en rayo justiciero. Clava la mirada profética en la risueña tierra prometida por las instituciones republicanas, y con un grito que conmueve al universo, enciende la inmensa hoguera que redujo a cenizas el edificio de tres siglos de despotismo. ¿Quién no lo ha reconocido? Es el mejor Hidalgo de D. Carlos María de Bustamante.

\section{VIII}

Estamos ya en la senda que conduce al altar que le tiene reservado a Hidalgo la gratitud nacional. La premura impide recorrerla en detalle, pero no hemos de renunciar del todo a tan interesante excursión.

A lo largo de los once años de vigencia de la primera república federal comienza a distinguirse a Hidalgo por encima de sus compañeros de conspiración y de armas. En 1825 la ciudad de México celebra por primera vez el aniversario del 16 de septiembre con gran discurso apologético del héroe. Al año siguiente se publica en El Iris, también por primera vez, su retrato, y dos años más tarde, aparece de nuevo en el precioso álbum de Claudio Linati con un texto que le atribuye toda la responsabilidad y gloria de la rebelión. Se le ve de pie y de cuerpo entero vistiendo un extravagante traje de campaña, cubierta la cabeza por un sombrero de anchas alas coronado con plumas. Seguramente priva mucho la fantasía en la indumentaria, pero quizá no tanto como se ha supuesto, según noticias que hay sobre el particular. La imagen es la de un hómbre robusto, más congruente con las hazañas, nos parece, que la del frágil anciano a que estamos acostumbrados. En el mismo año se le concedió a la Villa de Guadalupe el rango de ciudad con el apellido de Hidalgo, y en Morelia, en una no muy afortunada oración fúnebre pronunciada un 16 de septiembre, sale muy mal parado Hernán Cortés en la anacrónica comparación que se le hace con el Cura. El orador, por otra parte; llora la ausencia del héroe, porque le parece que habria sabido impedir la legislación anticlerical de los años 33 y 34 . Mucho tendrá que llover para que después de este aislado conato se decida la Iglesia, en la desenvuelta pluma de un conocido historiador jesuita, a reclamar a $\mathrm{Hi}$ dalgo como suyo.

Pero pese a esa creciente exaltación de Hidalgo, aparecen síntomas iturbidistas al tocar a su fin el régimen federal. Así, por ejemplo, la publicación en México del Manifiesto que escribió Iturbide en el destierro; el brindis de D. Lucas Alamán, célebre porque junto al elogio del exemperador, calificó -parece mentira en él- de "varones esclarecidos" a los insurgentes, y finalmente, el Ensayo histórico de D. Lorenzo de Zavala donde se aplaude mucho el Plan de Iguala, se le niega a Hidalgo el haber tenido un programa 
político y militar y se ridiculiza la idea de atribuirle propósitos republicanos. Y ya muy cercana la implantación del sistema centralista, el General Santa-Anna, principal motor que fue de la caida de Iturbide, tuvo a bien iniciar la rehabilitación oficial de su memoria, decretando que la patria lo reconocía "como uno de los principales autores de la independencia" y mandando que se trajeran sus cenizas a la Capital para depositarlas en la misma urna donde estaban las de Hidalgo, proyecto que no se realizó y tạn desacertado como sería el de traer los restos del general Porfirio Diaz para enterrarlos en la fosa de Madero.

\section{IX}

Si, como hemos visto, se vinculó la memoria de Hidalgo al régimen federal, ya se habrá columbrado que Iturbide será el héroe del sistema centralista. $Y$ en efecto, en curioso paralelismo los once años de este regimen ofrecen a ese propósito un cuadro parecido al de los también once de la República Federal. Como si se tratara de una competencia deportiva, le toca a Iturbide el desquite. Igual que el de Hidalgo, su nombre fue inscrito en letras de oro en el salón del Congreso; sus cenizas también fueron traidas a México y solemnemente depositadas en Catedral, pero en urna separada y no en el altar de Los Reyes, sino en la capilla de San Felipe, y por último, el 27 de septiembre fue rehabilitado como festividad pública y conmemorado por primera vez y con pompa inusitada.

Todo eso fue obra de Santa-Anna; pero envidioso de la gloria de su héroe no tardó en querer participar en ella. Se recordará que el 11. de septiembre de 1829 aquel jefe había batido con singular fortuna en Tampico el amago de invasión española al mando del brigadier Barradas. Se le ocurrió que esa era la fecha que en verdad correspondía a la consumación de la independencia y que, por lo tanto, debería conmemorarse su aniversario como fiesta nacional. Así lo decretó, y para mejor consagrarla tuvo la idea de levantar un monumento a la independencia en la Plaza de Armas. N̦o se pasó de la ceremonia de la primera piedra y de quitar el estorbo del Parián; pero lo interesante para nosotros es el proyecto que se pretendía construir. Su autor fue D. Lorenzo de la Hidalga, ganador del concurso por determinación de Santa-Anna en contra del dictamen de la Academia. $Y$ es que aquel ilustre arquitecto supo halagar la vanidad del Presidente. Ideó una columna en cuyo pedestal habria cuatro frisos que recordaban las ahora cuatro fechas culminantes de la lucha por la independencia: el grito de Dolores, el Plan de Iguala, la entrada a México del Ejército Trigarante y claro está, la derrota de Barradas en Tampico. Convertido así el General-Presidente en héroe de aquella gloriosa guerra, mandó hacerse una estatua ecuestre que se colocó en la Plaza del Mercado Nuevo, también obra ejecutada por sus órdenes, y como es de suponer, la fiesta de Iturbide padeció mucho en lucimiento comparada con la del día once.

Esta intrusión de Santa-Anna no deja de ser un episodio pasajero de servilismo y de vanidad. Positiva importancia tiene, en cambio, la aparición en este periodo del México y sus revoluciones del Dr. Mora; del "Suplemento" de Bustamente a Los tres siglos del P. Cavo, y del texto de un discurso de 16 de septiembre 
pronunciado por su Illma. el Dr. D. Clemente de Jesús Munguía en la ciudad de su sede. Reconocidas las enormes diferencias que separan a estas tres producciones de índole e intención tan diversas, no dejan de coincidir en el elogio a Iturbide y aunque en diferencia de grados, en la opinión respecto a Hidalgo: en el Dr. Mora muy adverso, menos en el Obispo y sólo timidamente favorable en Bustamante.

$Y$ así, empatados nuestros dos héroes en la carrera de la fama, no tardará en sobrevenirle a México su más grande tragedia: la mutilación de su territorio a consecuencia de la guerra con los Estados Unidos de Norteamérica.

\section{$\mathbf{X}$}

El destierro de Santa-Anna en mayo de 1845 señala la primera crisis del Centralismo. El ascenso al poder del general Herrera creó un clima de simpatía hacia los insurgentes. D. Manuel Payno acababa de publicar una narración semi-histórica de muy dudoso gusto, pero significativa por ser la primera, que sepamos, donde la descripción de "el grito" se falsea en los colores que serán populares: repiques de libertad, arenga patriótica, vivas y mueras que no se exclamaron, y el Cura ya francamente el albo ancianito que se pondrá tan de moda. Quintana Roo, por su parte, propuso en un discurso el cambio del consabido Hidalgo mensajero de Dios por el del laico instrumento de la teleología histórica, y un poco más tarde, D. Luis de la Rosa, frente al amago monárquico, hace gala en una oración cívica de su hispanofobia e indofilia para destacar sobre ese fondo al Hidalgo republicano, el enemigo jurado de toda realeza.

No tardó mucho en regresar, disfrazado de liberal, el general Santa-Anna prometiendo la victoria contra el invasor. Desgraciadamente a éste no le estorbaron gran cosa los desplantes del Marte mexicano, y precisamente, en el aniversario del grito de Dolores, junto a las estrellas de Dios lucieron en el cielo de la Plaza de Armas las estrellas norteamericanas. La ironia de la fecha se le antojó admonitoria a D. Lucas Alamán que en la soledad de su gabinete trabajaba su formidable alegato histórico contra la insurgencia. Desterrado de nuevo el gran indispensable, la fortaleza de las instituciones federales quedó en poder de las fuerzas conservadoras que enarbolan a Iturbide. La ofensiva contra los insurgentes se desata en serio con un artículo de fondo en El Universal que bien pudo haber firmado el propio Iturbide. "El grito de Dolores, se dice, no tuvo por objeto la independencia, ni fue expresión de los mexicanos" y nada casual tiene la coincidencia en la tesis y en la fecha con la aparición de los dos primeros tomos de la Historia de Alamán. A la proscripción de los insurgentes sólo le falta la. ofensa a su primer caudillo. Se trataba de bautizar a un nuevo Estado de la República, y con notoria intención de procrastinar a Hidalgo se elige un nombre insurgente, el de Guerrero, claro está, por lo de Acatempan. Y llegado septiembre -estamos en 1850- la gran fiesta fue el 27, no el 16, y los grandes lutos el 28, no el 17, solemnizados con honras por el alma, dice el decreto respectivo, "del inmortal héroe de Iguala".

Como por milagro hay un breve paréntesis liberal. El Estado de 
México lo aprovecha para desagravio de Hidalgo y le levanta una estatua en Toluca, la primera (1851) de las mil y una que después le irán brotando a las plazas y jardines de la República. Pero predominante de nuevo el partido conservador, el abismo entre Hidalgo e Iturbide se abre más profundo con la aparición de los últimos volúmenes del libro de Alamán. En vano D. Melchor Ocampo alża la voz en un discurso que quiere conciliar a los dos héroes en una sintesis de gratitud, porque sus acentos se ahogan en el estruendo de sables y espuelas que anuncia el orto de la estrella santannista que con resplandores monárquicos hunde en la sombra lo que quedaba de federación.

Desfiles y banquetes conmemoran de nuevo el arrumbado aniversario de la derrota de Barradas, y se implanta por segunda vez el sistema centralista bajo la égida de Iturbide. En una ceremonia luctuosa de gran romanticismo se celebran honras en Catedral a vista del corazón de Anastasio Bustamante, para depositarlo, después, como lo había deseado su dueño, en la urna de Iturbide. Ave Fénix de los gobiernos conservadores, renace de sus cenizas la Orden de Guadalupe y en el registro de sus caballeros grandes cruces se anotan el nombre de Iturbide, su fundador, y los de O'Donojú y Guerrero. Como años atrás a Hidalgo, ahora le toca a Iturbide el reconocimiento por ley de sus hazañas, porque "¿qué mayor servicio, pregunta el legislador, que haber constituido a la nación en. independiente y libre?" Otórguesele, pues, el dictado de "El libertador".

Una gran desgracia le ocurre al partido monárquico: la muerte de D. Lucas Alamán. Ya sin el freno de la inteligencia, Santanna se deja ir por la pendiente de su locura. Armado de facultades omnimodas se perpetúa en el poder con el tratamiento de Alteza Serenísima, el mismo, se recordará, que se dejó dar Hidalgo en los días de su envanecimiento, y quizá por esa coincidencia, pero más bien por la necesidad de atraerse a los liberales ya muy amenazadores, también el nombre de Hidalgo y de los otros jefes insurgentes fueron inscritos en grandes cruces de Guadalupe por mandato del dictador.

La revolución de Ayutla fue popular y fue incontenible. Ahora sí, Santa-Anna se ausentará para siempre de la historia, y no deja de conmover un poco que su canto de cisne en el poder haya sido decretar día de luto nacional el aniversario del fusilamiento de Iturbide.

\section{$\mathbf{X I}$}

El ascenso de Hidalgo ya no encontrará tropiezos, porque aún en tiempos del Segundo Imperio, que trató de arraigarse a la sombra de Iturbide, no habrá hostilidad hacia el Cura. Pero volvamos al momento de la caída de Santa-Anna. Por lo pronto no se ataca la memoria de Iturbide, y hasta tal punto era ya un hábito invocarla que eso se hizo en el preámbulo del Plan de Ayutla, desliz político que se precipitó a corregir Comonfort en su Plan de Acapulco. Por estas fechas D. Manuel Orozco y Berra intentó que se volviera a la idea de concebir como un solo acontecimiento las revoluciones de 1810 y 1821 y aconseja la tolerancia al juzgar la 
conducta de sus jefes. Débil dique a la pasión política que se desbordará a torrentes. En sucesión a corto plazo aparecen las señales de la futura predominancia de Hidalgo. Se quiso, por ejemplo, poner bajo la protección de su sombra al Congreso Constituyente que, según la Ley de Convocatoria, deberia reunirse en la ciudad de Dolores; se pensó en Aguascalientes para ciudad federal, pero mudándole el feo nombre por el de Hidalgo, y su efigie aparece en los primeros timbres postales que por estas fechas se expidieron en México. Más significativos son los discursos de aniversario del 16 de septiembre, entre los que merece la pena recordar uno de, Juan Diaz Covarrubias y otro de Melchor Ocampo. En el primero, luce Hidalgo en su cada vez más exagerada senilidad, como el olvidado, el pobre y bondadoso cura que, dice el orador, muere con el perdón en los labios. En el segundo, Iturbide ni fue un héroe, ni beneméritos fueron sus servicios. Iguala, dice Ocampo con olvido de su declamación anterior, representa el artero ardid de los vencidos que estafó el candor de los vencedores, aludiendo así, quién sabe con qué fundamento, a los insurgentes de quienes se puede decir todo menos eso.

Desvinculadas de nuevo en la compresión histórica las dos revoluciones, los liberales se aprestan a la batalla con su anciano por escudo. De momento la imagen es la adecuada, porque la senectud se asocia naturalmente a la idea de paternidad. Ignacio Ramírez señaló la obvia conexión. Los mexicanos, dice, no descendemos del indio, ni del español; descendemos de Hidalgo que por eso es verdaderamente el padre de la patria. Pero las circunstancias pedian algo más eficaz para oponer a las huestes napoleónicas que un viejecito de trémula mano, y haciendo honor al seudónimo, también será Ramírez el encargado de realizar la necesaria transformación. Lo que cuenta en Hidalgo, dice en un discurso famoso, no son ni las creencias, ni las costumbres. Anciano, sí, pero rejuvenecido por el amor a la patria, lo que hace de él un verdadero héroe, fue su antorcha de destrucción, su evangelio de la espada. El Hidalgo que cuenta es, pues, el iracundo inspirador del "mueran los gachupines", el terrible ángel de la guerra sin cuartel. Sólo su ejemplo, concluye El Nigromante, conducirá a la República a la victoria.

Queda en el arcano si esa fue o no la causa del triunfo de las armas mexicanas. Lo cierto es que fusilados los conservadores en las personas del Archiduque y de sus generales, más que el Atila de Dolores importa ahora exhibir al patricio venerable como raiz histórica de las instituciones victoriosas. $Y$ así fue cómo a medio siglo de distancia de su muerte le llegó a Hidalgo, por fin, su consagración más alta como divinidad rectora de la patria. Y no incurrimos en anfibología: en dos discursos claves de Ignacio Altamirano se fraguó el ídolo. Cargado el acento geriátrico y enterrado el mensaje de odio, vemos ascender a Hidalgo, entre guirnaldas e incienso, a los altares cívicos en la advocación de "Divino anciano". Fue su mocedad, dice el orador, entrega a la ciencia y a la belleza, aludiendo a sus devaneos amorosos. Cultivó en la madurez el campo y la artesanía, y tocado de la mano del destino, ya anciano engendró a la patria con su inmenso amor de ciudadano, legislador y mártir. Sólo con idolatría, concluye, se paga a $\mathrm{Hi}$ dalgo. 


\section{XII}

Ha llegado el momento de cortar el hilo a esta historia. Está dicho, me parece, lo más que cabia decir en tan poco espacio. Para conclusión baste añadir que al encumbramiento idolátrico siguió la propagación del culto con su abundante cosecha de altares y de honores y sus grandes apoteosis en las fechas centenarias. De mayor interés sería rastrear el desarrollo del proceso ideológico que tuvo por punto de partida la canonización histórica de Hidalgo. D. Gabino Barreda lo hace el propulsor mexicano de la ley de los tres estados; D. Anastasio Zerecero se esfuerza lo indecible por inmacularlo; se divulga como fuente de la mayor importancia histórica el endeble y piadoso relato de Sotelo, y Baz escribe la primera biografia del héroe para presentarlo tal como le gustaba a la Reforma: anciano, no creyente, filósofo, verdadero iniciador de la independencia, republicano e inmaculado; pero, contradicción flagrante, sacerdote católico prejuiciado cuando se trata de explicar su retractación a la hora de la muerte. Poco después una Comisión del Congreso insiste mucho en el Hidalgo pensador a cambio del sacerdote, y de la misma época es una feroz requisitoria de Altamirano contra Iturbide. Este, el arrogante, es motivo de una comparación que hace Gutiérrez Nájera con el humilde "viejecito de canas inmaculadas" que, si hemos de creer al poeta, le inspiraban vehementes deseos osculatorios. D. Francisco Sosa, el liberal a quien ya no le daban náuseas los arzobispos, compendía la obra de Baz, pero con la increíble valentía de atreverse a decir que el degüello de inocentes españoles no era cosa de aplaudirle a Hidalgo, y esta censura es una especie de permiso para la aparición de obras que unos años antes no se habrian tolerado, como son la de Julio Zárate, José de la Fuente, Francisco Bulnes y Justo Sierra. Apologéticas todas en diverso grado, tienen en común, la intención de recortar las exageraciones de los oradores de aniversario y de crear un ambiente más comprensivo hacia España y su empresa colonizadora. Zárate nos ha dejado la imagen porfirista de $\mathrm{Hi}$ dalgo, la que vemos, en mármol, presidiendo la Columna de la Independencia; el Hidalgo intimo de José de la Fuente podía ser un poco más íntimo, pero vale por su saludable regreso a los testimonios; Francisco Bulnes presenta el mejor alegato contra Alamán, porque tiene la inteligencia de concederle lo que es menester conceder y rompe una lanza en favor de Iturbide, y Justo Sierra, siempre tan perspicaz, le prepara a Hidalgo su segunda ascensión al renovarle el motivo de sus laureles. En su tersa prosa se esfuma el ancianito doblegado que, dicho sea de paso, sólo tenía cincuenta y ocho años cuando lo fusilaron, y con él desaparece el heraldo republicano, puesto que, según Sierra, Hidalgo carecía de todo plan político digno de ese nombre. Lo importante, explica, no fueron las ideas políticas que pudo haber tenido el caudillo; lo importante es que su revolución fue "eminentemente social". Ya algo de eso se habia dicho, pero no así, ni en momento tan preñado, como que ya estaba en puertas la revolución maderista. He aquí el germen del nuevo Hidalgo, el de nuestros días, el profético precursos del programa revolucionario, porque como el pasado es fuente inagotable de posibilidades, sobre todo cuando se le sujeta a cues: tión de tormento, el agrarismo, el obrerismo, el sindicalismo, la 
educación de las masas, el indigenismo, la enseñanza politécnica, el socialismo, la intervención estatal en la economía y qué sé yo cuántas otras benéficas teorias que inexorablemente van empujando al mundo hacia una espléndida barbarie, han querido encontrar su origen y agresividad en D. Miguel Hidalgo a quien, por misión cumplida ¿no será ya tiempo, pregunto, de rescatarlo de sus estatuas y de quitarle las botas de campaña? 